\title{
NOTE
}

\section{Development of Anguillicola crassus (Dracunculoidea, Anguillicolidae) in experimentally infected Balearic congers Ariosoma balearicum (Anguilloidea, Congridae)}

\author{
Bernd Sures*, Klaus Knopf, Horst Taraschewski \\ Zoologisches Institut I - Parasitologie/Ökologie, Universität Karlsruhe (T.H.), 76128 Karlsruhe, Germany
}

\begin{abstract}
The development of Anguillicola crassus in experimentally infected Ariosoma balearicum (Anguilloidea, Congridae) kept in seawater was studied in the laboratory. In parallel trials the effect of water salinity on the development of larval A. crassus in European eels Anguilla anguilla was also investigated using eels kept in seawater of a salinity of $34 \%$. Both eel species were orally inoculated with $\mathrm{L}_{3}$ larvae of A. crassus and then maintained for up to $3 \mathrm{mo}$ at $18^{\circ} \mathrm{C}$ in seawater. $110 \mathrm{~d}$ post infection, no adult but larval $\left(\mathrm{L}_{3}\right.$ and $\left.\mathrm{L}_{4}\right)$ stages of $A$. crassus were detected in the swimbladder wall of Balearic congers, although this period of time was sufficient for the parasites to develop to the adult stage in European eel kept in seawater. The results presented suggest that the definitive host specificity of $A$. crassus comprises species of the family Anguillidae (i.e. the genus Anguilla), but not members of the Congridae. Theoretically however, A. balearicum might serve as a metaparatenic host. Factors determining the definitive host range of $A$. crassus remain to be elucidated. Water salinity does not seem to act as a factor affecting definitive host specificity once the parasite has become ingested by the eel.
\end{abstract}

KEY WORDS: Anguillicola crassus - Anguilla anguilla Ariosoma balearicum Development - Salinity - Metaparatenic host

Nematodes of the genus Anguillicola are widely distributed swimbladder parasites of eels. Anguillicola species have been recorded from various eel species of the monotypic family Anguillidae as definitive hosts (Moravec \& Taraschewski 1988). Anguillicola crassus has been very successful in colonising eel species and their populations by transcontinental displacement and then by a quick spread within the continent. Originating from East Asia where it naturally parasitized Anguilla japonica and later on also cultivated Euro-

•E-mail: bernd.sures@bio-geo.uni-karlsruhe.de pean eels Anguilla anguilla (see Nagasawa et al. 1994), A. crassus became a very abundant parasite in A. anguilla throughout Europe (Würtz et al. 1998, Sures et al. 1999) and North Africa (El Hilali et al. 1996, Maamouri et al. 1999) in the 1980s and 1990s. From 1995 the parasite also occurred and reproduced in the American eel Anguilla rostrata along the east coast of the United States (Johnson et al. 1995, Fries \& Williams 1996, Barse \& Secor 1999). At present, 3 members of the genus Anguilla are known to serve as final hosts of $A$. crassus, while various other fish species as well as amphibians and even invertebrates may serve as paratenic hosts (Moravec \& Konecny 1994, Moravec 1996, Székely 1996, Moravec \& Skoriková 1998).

The successful spread of Anguillicola crassus is also due to the ability of the nematode to survive and reproduce in eels under many conditions that the host can withstand. In European eels caught in freshwater, adult $A$. crassus did not become negatively affected when the hosts were maintained in water with salinities ranging from freshwater to $100 \%$ seawater over a period of 4 wk (Kennedy \& Fitch 1990). In nature, transmission of $A$. crassus occurs in brackish water lagoons with salinities ranging between 10 and $40 \%$ (Kennedy et al. 1996) as well as in the Baltic Sea (Höglund et al. 1992, Reimer et al. 1994). Accordingly, marine eel species belonging to the family Congridae may ingest $L_{3}$ larvae and become infected with $A$. crassus.

It was the aim of the present investigation to check whether the final host range of Anguillicola crassus includes Anguilliformes of the family Congridae or whether it is limited to the family Anguillidae, i.e. the genus Anguilla. As the water salinity obviously did not affect the development and viability of $A$. crassus in Anguilla anguilla, the Balearic conger Ariosoma bale- 
aricum was used to investigate the final host specificity of the nematode under marine conditions.

Material and methods. European eels Anguilla anguilla L., 1758 (Anguilloidea, Anguillidae) with a length ranging between 35 and $45 \mathrm{~cm}$ were obtained from a commercial fish farm (Limnotherm, Bergheim, Germany) known to be free of Anguillicola crassus. 3 eels were placed in a $100 \mathrm{l}$ tank and maintained in aerated water with a salinity of $34 \%$ at a water temperature of $18^{\circ} \mathrm{C}$. The eels were allowed to adapt to the salinity step by step by adding marine salt to tap water each week until a final salinity of $34 \%$ was reached after $6 \mathrm{wk}$.

3 Balearic conger Ariosoma balearicum Delaroche, 1809 (Anguilloidea, Congridae) with a length ranging between 28 and $34 \mathrm{~cm}$ caught in the Mediterranean Sea near the Island of Giglio (Italy) were transported alive to the laboratory, placed in a $100 \mathrm{l}$ tank and maintained in aerated seawater $(34 \%$ ) at a water temperature of $18^{\circ} \mathrm{C}$.

Anguilla anguilla as well as Ariosoma balearicum were infected with third-stage larvae $\left(\mathrm{L}_{3}\right)$ of Anguillicola crassus perorally with a stomach tube. Freshwater eels were inoculated with 7 larvae while the marine eels were infected with $40 \mathrm{~L}_{3}$. The third-stage larvae were obtained by feeding second-stage larvae $\left(\mathrm{L}_{2}\right)$ from the swimbladder lumen of naturally infected eels to planktonic copepods, mainly comprising Thermocyclops cf. crassus and Mesocyclops leuckarti (for details see Knopf et al. 1998). Immediately after infection the fish were placed back in seawater and maintained unfed for up to $110 \mathrm{~d}$ under marine conditions. At the end of the experiment the fish were killed and the swimbladder was examined for living and dead larvae and adults of $A$. crassus. $\mathrm{As}_{3}$ and $\mathrm{L}_{4}$ cannot be distinguished from each other perfectly by means of light microscopy (Blanc et al. 1992), all larvae with a body length exceeding $1.5 \mathrm{~mm}$ were counted as $\mathrm{L}_{4}$ according to the suggestion of Knopf et al. (1998).

Results and discussion. Only 1 out of 3 Anguilla anguilla which were adapted to seawater and then infected with $L_{3}$ larvae survived over several months. This individual was killed at $110 \mathrm{~d}$ post infection (p.i.). Its swimbladder contained 1 male adult Anguillicola crassus. As neither $\mathrm{L}_{3}$ nor $\mathrm{L}_{4}$ were found, the recovery rate could be given as $14 \%$. This result confirms the finding of Kennedy \& Fitch (1990) that A. crassus can establish and survive in $A$. anguilla under marine conditions, although infection levels decrease with an increase in salinity (Kirk et al. in press).

In contrast, only 1 Ariosoma balearicum died after $34 \mathrm{~d}$ p.i. In the swimbladder of this eel $67 \% \mathrm{~L}_{3}$ and $33 \% \mathrm{~L}_{4}$ were recorded (Fig. 1). This ratio had changed to values of $33 \% \mathrm{~L}_{3}$ and $67 \% \mathrm{~L}_{4}$ in the second eel maintained for $110 \mathrm{~d}$ p.i. The third $A$. balearicum was found

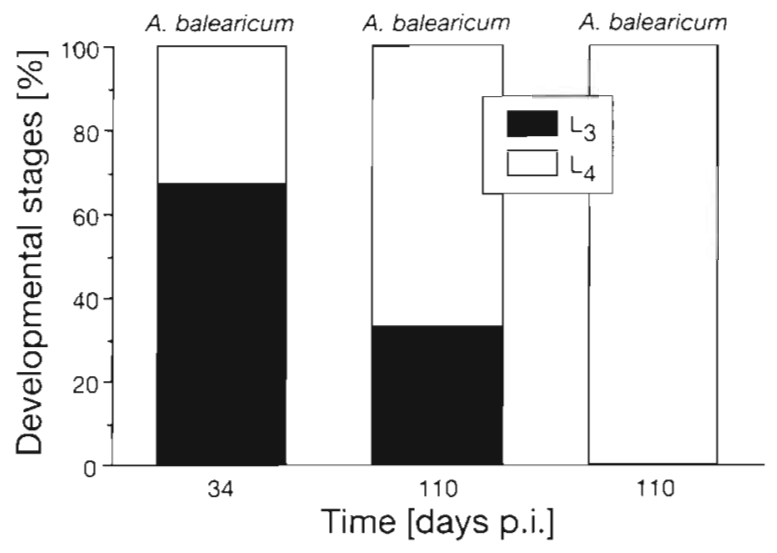

Fig. 1. Relative percentages $(\%)$ of different developmental stages of Anguillicola crassus out of the total number of specimens recovered from the swimbladder of 3 specimens of Ariosoma balearicum kept in seawater

to contain only $\mathrm{L}_{4}$ at $110 \mathrm{~d}$ p.i. The recovery rates could be given as $15 \%$ for the first $2 \mathrm{~A}$. balearicum and $10 \%$ for the third eel. Thus, it is obvious that $\mathrm{L}_{3}$ larvae of Anguillicola crassus are able to moult to the $\mathrm{L}_{4}$ stage in the swimbladder wall of A. balearicum. However, although the period of time was long enough for a complete development into the adult stage, no adult worms were recorded in the lumen of swimbladders of $A$, balearicum.

In a recent study Knopf et al. (1998) elucidated the time required for complete development of $\mathrm{L}_{3}$ larvae in European eels kept in freshwater at a temperature of $18^{\circ} \mathrm{C}$. First adult worms $(12 \%)$ were recorded $50 \mathrm{~d}$ p.i., reaching values of approximately $85 \%$ of the total number of recovered worms on Day 80 p.i. From this day onwards the ratio of larval stages $\left(\mathrm{L}_{3}\right.$ and $\mathrm{L}_{4}$ ) changed only little and remained below 15\%. A developmental period of approximately $50 \mathrm{~d}$ at $18^{\circ} \mathrm{C}$ (Knopf et al. 1998) is consistent with earlier results of Haenen et al. (1996), who first observed Anguillicola crassus in the swimbladder lumen of eels $48 \mathrm{~d}$ p.i. at 18 to $20^{\circ} \mathrm{C}$. Following Day 80 p.i., more than $80 \%$ of the worms became adult and this ratio remained nearly unchanged until Day 110 p.i. (Knopf et al. 1998). Thus, a period of $110 \mathrm{~d}$ should also be sufficient for $A$. crassus to develop in Ariosoma balearicum to the adult stage. The fact that in Balearic congers $A$. crassus did not reach the adult or at least the preadult stage but just moulted from the third-stage larvae into the fourthstage larvae is most likely due to host-specific factors and not due to the water salinity, as can be concluded from the parallel experiment with European eels. Obviously, the host range of $A$. crassus does not include true seawater eels (congers) like A. balearicum, although the salinity itself does not act as the limiting factor. More likely, the final host range only comprises 


\begin{tabular}{|l|l|l|l|l|l|l|}
\hline Order & Suborder \\
Family
\end{tabular}

Fig. 2. Taxonomic position of fish species (Deckert et al. 1991) found to act as definitive or metaparatenic hosts for Anguillicola crassus. Data are from this paper and from the literature (De Charleroy 1990, Haenen \& Van Banning 1990, Thomas \& Ollevier 1992, Reimer et al. 1994, Moravec 1996)

members of the monotypic family Anguillidae (Tesch 1999) but not marine eels of the family Congridae.

In a field study Reimer et al. (1994) described the deep-snouted pipefish Syngnathus typhle as a potential paratenic host of Anguillicola crassus naturally containing fourth larval stages of the parasite. Additionally, different freshwater fish species are known to act as such metaparatenic (stadiogenous) hosts or even paradefinitive hosts (see Odening 1976, Moravec \& Konecny 1994, Moravec 1996), enabling the parasite to develop into the $\mathrm{L}_{4}$ larval stage (De Charleroy et ai. 1990, Haenen \& Van Banning 1990, Thomas \& Ollevier 1992, Moravec 1996). The systematic positions (according to Deckert et al. 1991) of the definitive and metaparatenic hosts of $A$. crassus so far described are summarised in Fig. 2. In addition to the 3-spined stickleback Gasterosteus aculeatus and S. typhle, both belonging to the order Gasterosteiformes, 3 species known to serve as metaparatenic hosts are the perciform fish species Gymnocephalus cernua, Perca fluviatilis and Lepomis gibbosus. It seems most likely that other perciform fish could also be found infected with $\mathrm{L}_{4}$ larvae of A. crassus, as the suborder Percoidea contains 26 families. As for salmoniformes, only Osmerus eperlanus was found to be infected with $\mathrm{L}_{4}$ larvae (Haenen \& Van Banning 1990), whereas no larval stages of $A$. crassus could be detected in Salmo trutta fario and Salmo salar in a field study by Thomas \& Ollevier (1992). Following the conception and terminology of Odening (1976), cyprinids, one of the biggest groups of freshwater fish, seem to belong to the euparatenic (astadiogenous) hosts, as only $\mathrm{L}_{3}$ larvae were recorded in the species investigated (Haenen \& Van Banning 1990, Moravec \& Konecny 1994, Székely 1995). In all, more than 30 fish species are known to act as such euparatenic hosts (Székely 1995, Moravec 1996).
Until now, 7 different fish species, including the Balearic conger, are known to act as potential metaparatenic hosts. Among them, 4 fish species are either truly marine fish or at least able to live in brackish water (Balearic conger, deep-snouted pipefish, smelt, 3-spined stickleback) and 3 are freshwater fish (river perch, ruffe and pumpkinseed). Thus, a relatively broad range of possible metaparatenic hosts for Anguillicola crassus seems to exist in every habitat which will be invaded by eels in the run of their life cycle. However, one still does not know to what extent intermediate hosts and the different categories of paratenic hosts contribute to the maintenance of the parasite's life cycle.

\section{LITERATURE CITED}

Barse AM, Secor DH (1999) An exotic nematode parasite of the American eel. Fisheries 24:6-10

Blanc G, Bonneau S, Biagianti S, Petter AJ (1992) Description of the larval stages of Anguillicola crassus (Nematoda, Dracunculoidea) using light and scanning electron microscopy. Aquat Living Resour 5:307-318

De Charleroy D, Grisez L, Thomas K, Belpaire C, Ollevier F (1990) The life cycle of Anguillicola crassus. Dis Aquat Org 8:77-84

Deckert K, Deckert G, Freytag GE, Günther K, Peters G, Sterba G (1991) Urania Tierreich, Vol 4, Fische, Lurche, Kriechtiere. Urania Verlag, Leipzig

El Hilali M, Yahyaoui A, Sadak A, Macchi M, Taghy Z (1996) Data on anguillicolosis observed for the first time in Morocco. Bull Fr Pêche Piscic 340: 57-60

Fries LT, Williams DJ (1996) Occurrence of Anguillicola crassus, an exotic parasitic swim bladder nematode of eels, in the southeastern United States. Trans Am Fish Soc 125: $794-797$

Haenen OLM, Van Banning P (1990) Detection of larvae of Anguillicola crassus (an eel swimbladder nematode) in freshwater fish species. Aquaculture 87:103-109 
Haenen OLM, Van Wijngaarden TAM, Van der Heijden MHT, Höglund J, Comelissen JBJW, Van Lengoed LAMG, Borgsteede FHM, Van Muiswinkel WB (1996) Effects of experimental infections with different doses of Anguillicola crassus (Nematoda, Dracunculoidea) on European eel (Anguilla anguilla). Aquaculture 141:41-57

Höglund J, Andersson J, Wickström H, Reizenstein M (1992) The distribution of Anguillicola in Sweden and its association with thermal discharge areas. Ir Fish Invest 36 $143-150$

Johnson SK, Fries LT, Williams J, Huffman DG (1995) Presence of the parasitic swim bladder nematode, Anguillicola crassus, in Texas aquaculture. World Aquaculture 26: $35-36$

Kennedy C, Fitch DJ (1990) Colonization, larval survival and epidemiology of the nematode Anguillicola crassus, parasitic in the eel, Anguilla anguilla, in Britain. J Fish Biol 36:117-131

Kennedy CR, Di Cave D, Berrilli F, Orecchia P (1996) Composition and structure of helminth communities in eels $A n-$ guilla anguilla from Italian coastal lagoons. J Helminthol 71:35-40

Kirk RS, Kennedy CR, Lewis JW (in press) The effect of salinity on hatching, survival and infectivity of Anguillicola crassus (Nematoda: Dracunculoidea) larvae. Dis Aquat Org

Knopf K, Würtz J, Sures B, Taraschewski H (1998) Impact of low water temperature on the development of Anguillicola crassus in the final host Anguilla anguilla. Dis Aquat Org 33:143-149

Maamouri F, Gargouri L, Ould Daddah M, Bouix G (1999) Occurrence of Anguillicola crassus (Nematode, Anguillicolidae) in the Ichkeul lake (Northern Tunisia). Bull Eur Assoc Fish Pathol 19:17-19

Moravec F (1996) Aquatic invertebrates (snails) as new paratenic hosts of Anguillicola crassus (Nematoda: Dracunculoidea) and the role of paratenic hosts in the life cycle of this parasite. Dis Aquat Org 27:237-239

Moravec F, Konecny R (1994) Some new data on the intermediate and paratenic hosts of the nematode Anguillicola crassus Kuwahara, Niimi \& Itagaki, 1974 (Dracuncu-

Editorial responsibility: Wolfgang Körting.

Hannover, Germany loidea), a swimbladder parasite of eels. Folia Parasitol 41:65-70

Moravec F, Skorikova B (1998) Amphibians and larvae of aquatic insects as new paratenic hosts of Anguillicola crassus (Nematoda: Dracunculoidea), a swimbladder parasite of eels. Dis Aquat Org 34:217-222

Moravec $F$, Taraschewski $H$ (1988) Revision of the genus Anguillicola Yamaguti, 1935 (Nematoda: Anguillicolidae) of the swimbladder of eels, including descriptions of two new species, A. novaezelandiae sp. n. and $A$. papernai sp. n. Folia Parasitol 35:125-146

Nagasawa K, Kim YG, Hirose H (1994) Anguillicola crassus and A. globiceps (Nematoda, Dracunculoidea) parasitic in the swimbladder of eels (Anguilla japonica and $A$. anguilla) in East Asia: a review. Folia Parasitol 41:127-137

Odening K (1976) Conception and terminology of hosts in parasitology. Adv Parasitol 14:1-93

Reimer L, Hildebrand A, Scharberth D, Walter U (1994) Anguillicola crassus in the Baltic Sea: field data supporting transmission in brackish waters. Dis Aquat Org 18: $77-79$

Sures B, Knopf K, Würtz J, Hirt J (1999) Richness and diversity of parasile communties in European eels Anguilla anguilla of the river Rhine, Germany, with special reference to helminth parasites. Parasitology 119:323-330

Székely C (1995) Dynamics of Anguillicola crassus (Nematoda: Dracunculoidea) larval infection in paratenic host fishes of lake Balaton, Hungary. Acta Vet Hung 43: $401-422$

Székely C (1996) Experimental studies on the infectivity of Anguillicola crassus third-stage larvae (Nematoda) from. paratenic hosts. Folia Parasitol 43:305-31.1

Tesch FW (1999) Der Aal. Blackwell Wissenschaftsverlag, Berlin

Thomas K, Ollevier F (1992) Paratenic hosts of the swimbladder nematode Anguillicola crassus. Dis Aquat Org 13: $165-174$

Würtz J, Knopf K, Taraschewski H (1998) Distribution and prevalence of Anguillicola crassus (Nematoda) in eels (Anguilla anguilla) of the rivers Rhine and Naab, Germany. Dis Aquat Org 32:137-143

Submitted: October 28, 1999; Accepted: November 15, 1999 Proofs received from author(s): December 1, 1999 